Article

\title{
Finding the Links between Risk Management and Project Success: Evidence from International Development Projects in Colombia
}

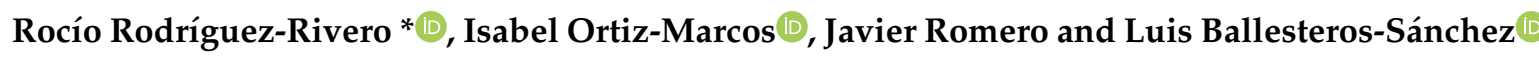 \\ Department of Organization, Business Administration and Statistics, Universidad Politécnica de Madrid, \\ C/José Gutiérrez Abascal 2, 28006 Madrid, Spain; isabel.ortiz@upm.es (I.O.-M.); javier.romero@upm.es (J.R.); \\ luisignacio.ballesteros@upm.es (L.B.-S.) \\ * Correspondence: rocio.rodriguez@upm.es
}

Received: 13 October 2020; Accepted: 5 November 2020; Published: 9 November 2020

check for updates

\begin{abstract}
The aim of this research is to help improve the effectiveness of international development projects (IDPs) with a focus on enhancing their success. For this purpose, this work seeks to identify links between the management of risks among five projects executed in Cauca (Colombia) and the success of these projects in terms of project management and impacts on the beneficiary communities. An analysis of these projects reveals the most critical risks encountered and the relationships between the management of those risks and the success of the projects. The use of fuzzy logic through the fuzzy-set qualitative comparative analysis (fsQCA) program is key to performing this difficult task. The results of a qualitative study reveal that the most important risks correspond to economic, cultural, and political factors. A quantitative analysis by fsQCA shows a direct relationship between the management of cultural differences and the positive impacts of IDPs on the beneficiary communities.
\end{abstract}

Keywords: project management; international development projects; risk management; project success; fuzzy logic; Colombia

\section{Introduction}

With investments in official development aid estimated by the Organization for Economic Cooperation and Development (OECD) [1] at \$143.22 billion in 2018 and with levels of hunger across the globe continuing to rise for the third consecutive year, affecting more than 820 million people (one in nine) [2], the effective management of international development projects (IDPs) is not only a commitment marked by the Paris Declaration [3] or a means to achieve goals set by the United Nations' 2030 Agenda [4] but also the responsibility of those who participate, in one way or another, in these projects.

The World Bank's Results and Performance report [5] records that approximately one in four IDPs financed by the World Bank does not achieve even moderate success. Those achieving highly satisfactory success are a small minority at 3\%, representing approximately 21 of 713 World Bank projects analyzed in the 2014-2016 period.

Among the possible causes of such low levels of success, the World Bank notes in previous reports the residual risks of projects. In turn, the World Bank's Results and Performance report [5] provides the first analysis relating levels of project risk to project success. The report finds a significant correlation between high residual risk rates and low project success.

Despite this finding, little research has been performed on IDP risk management, which is striking given that for other types of projects, risk management is considered a prominent area of project management (PM). Some exceptions include Couillard et al. [6] and Ika and Lytvynov [7], 
who incorporated a column on risk into the Logical Framework Matrix. In continuing this work, Rodríguez-Rivero et al. [8] pointed to the integration of risk management as the most valued improvement to the Logical Framework Approach. Hekala [9] also found risks inherent to IDPs to limit their impact, noting that while these risks are inevitable, they could be better controlled with better project planning and by developing project managers' skills.

Project success can be understood in two ways: success in project management and success in project impact. These two interpretations of success can occur independently. Traditionally, in the literature related to project management, successful PM is linked to efficiency mainly in terms of the well-known golden triangle (scope, cost, and time) and to effectiveness based on customer satisfaction [10].

While successful PM is also essential for IDPs, successful impacts on the beneficiary community also play an indispensable role, as the fundamental objective of these projects is to improve people's quality of life.

The present work explores the relationship between risk management and the success of projects in reference to various IDPs applied in Cauca (Colombia), as part of a Doctoral Thesis research [11]. The aim is to contribute to the success, in its double aspect, of future projects developed in Cauca. Only by knowing which risks are more important will it be possible to act on them; knowing which risks have more influence on success will also allow for the prioritization of strategies. Through the use of a fuzzy-set qualitative comparative analysis (fsQCA), this study seeks to evidence the causal links between managing risks and IDP success. Thus, in studying five IDPs in Cauca, and under the hypothesis that the success of IDP in Cauca depends on the proper management of its risks, this work aims to respond to two questions:

Research Question 1 (RQ1): What are the most critical risks that affect IDPs executed in Cauca?

Research Question 2 (RQ2): What is the relationship between managing such risks and the success of such projects?

In answering these questions, this work is organized as follows. A literature review first describes the main challenges facing IDPs today and describes the setting in Cauca, where the studied projects were executed. A methodological section then presents the projects considered along with qualitative methodologies used for risk assessment and quantitative methods used employing fuzzy techniques. Finally, the main results obtained are presented and discussed and conclusions are drawn.

\subsection{Challenges Facing International Development Projects}

Project ineffectiveness [12,13] and dependent relations between developed and developing countries $[14,15]$ have been identified as challenges to IDPs. This latter more critical vision is posed by theories of the postdevelopment field, which have gained prominence since the publication of Wolfgang Sachs's bestseller The development dictionary [16]. This movement understands that dominant notions of development linked to the economic growth of markets, productivity, and the satisfaction of insatiable desires for material goods respond to a Western economic model that disregards other possible dimensions of economic activity, such as the relationship to Mother Earth, which plays a significant role in agriculture, or concepts of sufficiency, solidarity, or community [17].

The concept of sustainability, which has grown more mainstream not only in the international community but in society itself, responds to a demand to meet needs while respecting the environment [18]. In introducing this environmental component, the multi-directionality of development emerges and with it some indigenous concepts such as Buen Vivir, which promotes productive and sustainable community development and which offers valuable lessons for international debate around the idea of sustainable development [19].

The classic work Development projects observed [20] placed IDPs at the core of development activities, and with them these projects have evolved from their origins to the present, as Figure 1 shows. 
Through the challenge of evolving towards more effective projects, many works have focused on identifying factors that influence the achievement of successful IDP impact [21-25].

While Denizer et al.'s [26] work based on data on 6000 World Bank projects concludes that in obtaining better results, variables related to a project itself such as its duration, budget, or control have a stronger influence than other variables related to the context of the country in which a project is implemented, many authors attach particular importance to the latter and to the influence of local contexts on IDP impacts [22,24,27-30]. In following this focus on local contexts, the present work analyzes Cauca in depth to identify risks most often encountered when executing an IDP.

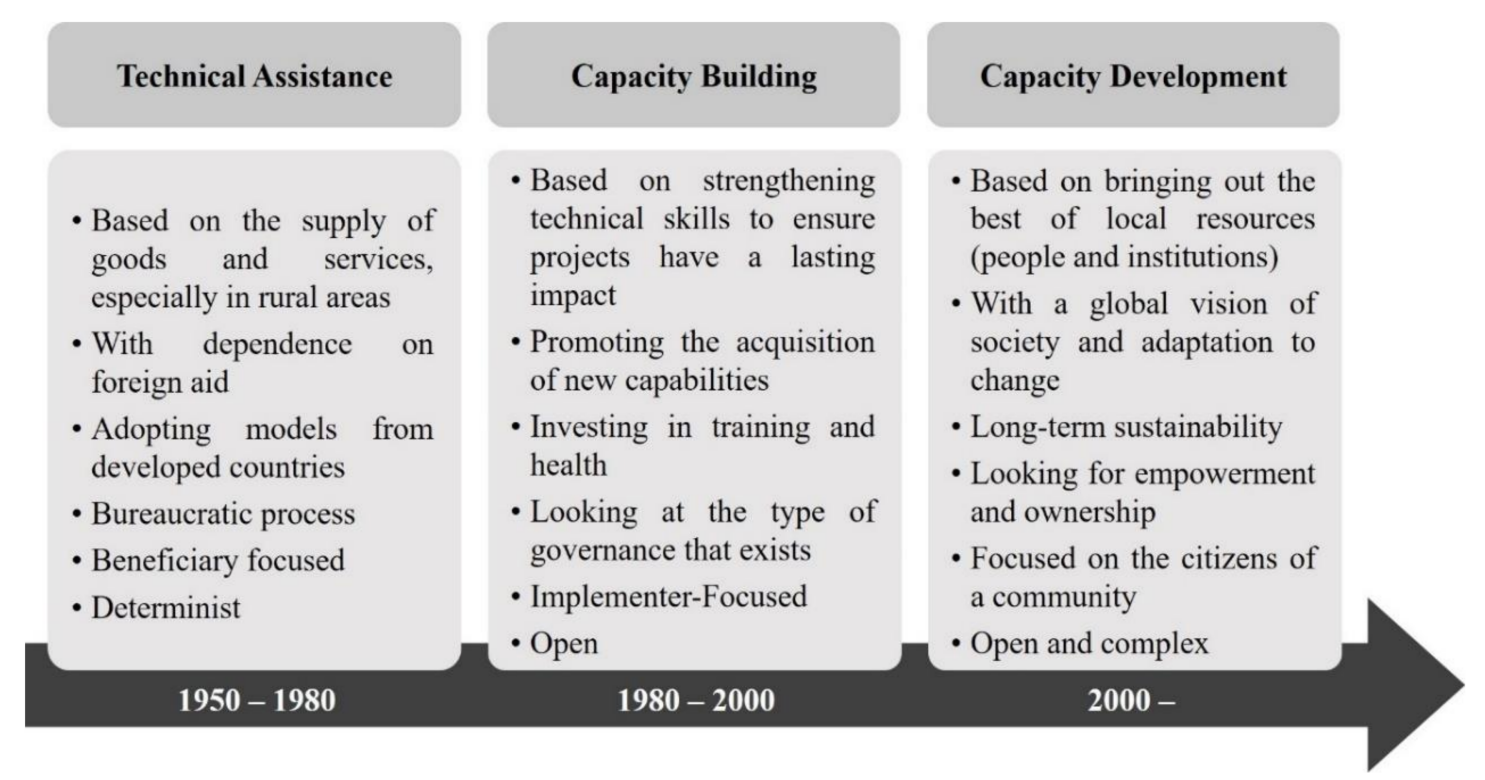

Figure 1. Evolution of international development projects. Based on the work of Ika [29], Ika and Hodgson [30], Boni [31], LenCD [32], and McEvoy et al. [33].

\subsection{The Context in Cauca (Colombia)}

Colombia has been studied as a special case characterized by rapid improvements in its population's quality of life and economic growth. For instance, mortality rates were reduced from 23.4 deaths per thousand inhabitants in 1905 to 5.5 in 2000 [34]. Economic growth has mainly been based on coffee exports and the extractive industry. Colombia is Latin America's fourth largest oil producer and the world's fourth largest coal producer [35]. Colombia is also the world's second largest producer of Arabica coffee, and its harvest in 2019/20 is forecasted to reach 14.1 million bags, $1.7 \%$ higher than that in 2018/19 [36]. Its human development index (HDI) is 0.761, placing it at 79 of 189, tied with Brazil [37]. Despite this development, neither its minerals or coffee nor its HDI currently gives Colombia as much global prominence as the end of its 50-year conflict, which officially ended in November 2016 and created the world's largest internally displaced population [38].

Many works published in recent years have focused on postconflict Colombia, highlighting among other factors issues related to sustainable development (e.g., Franco et al. [39], González-Salazar et al. [40], Nail [41]). Academics and politicians agree that progress in Colombia must be in line with the UN's Sustainable Development Goals (SDG) listed in its 2030 Agenda [4].

The department of Cauca with the capital of Popayán is in southwestern Colombia and includes 42 municipalities. Cauca is one of the departments hardest hit by the armed conflict in Colombia and is suffering the reconfiguration of an increase in armed groups in their eagerness to occupy territories left by the FARC-EP [42]. The department is also one of the areas with the highest extreme poverty rates in the country with $22.9 \%$ of the affected population, while this figure drops to $7.2 \%$ for the rest of Colombia [43]. Cauca is also distinct in its large indigenous (42.7\%) and rural populations (59.9\%) [44]. Levels of higher education are also lower here than in the rest of the country [45]. 
The United Nations Office for the Coordination of Humanitarian Affairs (OCHA) considers Cauca a priority area for action, defining most of its municipalities as of very high need since armed groups dispute over territorial and population control to manage illegal economies, which has triggered risks and a need for humanitarian and protection care. For example, between 2016 and 2018, 89 social leaders were assassinated in the area [42].

The critical situation in this department is recognized by the international community with numerous IDPs developing in the area.

\subsection{Project Management in International Development Projects}

Project life cycle management has been the principal methodology used for decades by donor countries and Non-Governmental Development Organizations (NGDO) for the management and assessment of IDPs $[33,46]$. While various tools have been developed under this methodology, the best known is the Logical Framework Approach (LFA). The evolution of development cooperation and associated projects has meant that international agencies and organizations have been adapting both the life cycles of their projects and the LFA [46].

Along with such methodologies, project teams have proved central in obtaining better IDP results [5,23]. While few studies have focused on the competencies of IDP project managers, Cobo [47] and Ortiz-Marcos et al. [48], in reference to development engineering projects, found that the most critical factors shaping successful project execution are related to the skills of project managers and team members and to their abilities to face changes, risks, and opportunities that may arise during project implementation (that is, their adaptability).

International projects and IDPs fail more often than projects at the national level due to a lack of training in intercultural skills among team members [49].

Working with different cultures implies a need to train in a series of competencies, including teams' and project managers' capacities to adapt to the environment in which a project is executed [50]. This adaptability is also highlighted by Ika and Donnelly [22] in studying 20 cooperating professionals of four IDPs.

Risk management, according to Kerzner [51], involves proactively and positively facing the risks of a project to enhance the likelihood of its success. Thus, risk management is increasingly understood as a process of increasing the probability of project success [52].

Zwikael and Ahn's [53] study of 700 project managers shows a negative correlation between risks and project success and that the effective application of risk management moderates the negative effects of risk. Other authors have also tried to relate risk management to project success in different types of projects as Research and Development (R\&D), construction, or Information and Technologies (IT), among others [54-60].

The present research seeks to link risk management to project success in the context of development cooperation based on a case study of Cauca (Colombia).

\section{Materials and Methods}

\subsection{Projects in Cauca}

The representativeness of the five selected IDPs executed in Cauca was determined over several stages. First, professionals from international organizations working in the field were consulted. Second, a thorough study of financing granted by international institutions to projects in Cauca was conducted. Finally, the Head of Cooperation of the Government of Cauca was consulted.

Information on the studied projects is presented in Table 1. Information provided by coordinators of the five IDPs was first compiled and analyzed. Then, workshops were held in the field with the team members of each project with a focus on the identification and assessment of risks and on perceptions of project success. Interviews based on open-ended questions were also conducted with project managers to contrast results obtained from the workshops and to identify any risk management 
activities executed during a project. Finally, additional validation of the results was conducted in consultation with the Head of Cooperation of the Government of Cauca.

Table 1. Descriptions of the studied projects.

\begin{tabular}{|c|c|c|c|c|c|}
\hline Id. Project & Project & Donor & Duration & $\begin{array}{c}\text { Direct } \\
\text { Beneficiaries }\end{array}$ & $\begin{array}{l}\text { Budget } \\
\text { (USA \$) }\end{array}$ \\
\hline P1 & $\begin{array}{l}\text { Access to higher education } \\
\text { institution among } \\
\text { rural youth }\end{array}$ & $\begin{array}{l}\text { Colombian } \\
\text { Government }\end{array}$ & Three years & 1035 rural youth & $1,094,232$ \\
\hline P2 & $\begin{array}{l}\text { Cultural industries as a } \\
\text { source of development }\end{array}$ & $\begin{array}{c}\text { Inter-American } \\
\text { Development Bank } \\
\text { (IADB) }\end{array}$ & Three years & $\begin{array}{l}51 \text { companies } \\
\text { (200 direct jobs) }\end{array}$ & $1,201,519$ \\
\hline P3 & $\begin{array}{l}\text { Microenterprises for } \\
\text { integrating displaced } \\
\text { populations }\end{array}$ & $\begin{array}{c}\text { International } \\
\text { Organization of } \\
\text { Migration (IOM) }\end{array}$ & One year & $\begin{array}{l}19 \text { micro-enterprises } \\
\text { (248 people) }\end{array}$ & 180,445 \\
\hline P4 & $\begin{array}{l}\text { Economic and social } \\
\text { empowerment of } \\
\text { rural women }\end{array}$ & EuropeAid & Two years & $\begin{array}{l}400 \text { women from } \\
\text { five municipalities }\end{array}$ & 812,692 \\
\hline P5 & $\begin{array}{l}\text { Productive processes for } \\
\text { allowing ETCR }\end{array}$ & $\begin{array}{c}\text { Swedish } \\
\text { Government }\end{array}$ & Nine months & 120 ex-combatants & 11,433 \\
\hline
\end{tabular}

The consulted project managers had more than 13 years of experience in international development and more than nine years of project management experience with the exception of the project manager of $\mathrm{P} 1$ who had five and four years of each form of experience, respectively. Project teams led varied from 30 people for P1 to four people for P5. The number of people who attended the workshops also varied for each project: 7 people for $\mathrm{P} 1,4$ people for $\mathrm{P} 2,3$ people for $\mathrm{P} 3,13$ people for $\mathrm{P} 4$, and 4 people for $\mathrm{P} 5$. The number of people who attended the workshop for project 4 is remarkable and it is convenient to emphasize that it was the only one that was in execution at that time, which facilitated the attendance.

The workshops were held at each team's headquarters in sessions lasting three hours on average. Sessions started by introducing the concept of risk management and the two main perspectives on project success: community impact and the fulfillment of objectives (project management). The participants then individually defined the concept of project success with each person allowed to provide up to three definitions, which were written on Post-it notes to encourage everyone's participation. The definitions were then grouped by the participants by consensus into a maximum of three factors. The session continued with the identification of risks. After being given examples and upon agreeing to work with the proposed Risk Breakdown Structure (RBS) presented in Figure 2, the participants jointly identified risks affecting or that could affect a project and listed these under the corresponding category. Assessments of the risks and different views of success identified were carried out individually based on a paper questionnaire with the format presented in Appendix A.

\section{RBS}

\begin{tabular}{|c|c|c|c|c|c|c|c|}
\hline $\begin{array}{l}\text { Environmental } \\
\text { (ENV) }\end{array}$ & $\begin{array}{l}\text { Cultural } \\
\text { (CUL) }\end{array}$ & $\begin{array}{c}\text { Project } \\
\text { Management } \\
\text { (PRO) }\end{array}$ & $\begin{array}{c}\text { Economic } \\
\text { (ECO) }\end{array}$ & $\begin{array}{l}\text { Organizational } \\
\text { (ORG) }\end{array}$ & $\begin{array}{l}\text { Political } \\
\text { (POL) }\end{array}$ & $\begin{array}{l}\text { Safety } \\
\text { (SAF) }\end{array}$ & $\begin{array}{l}\text { Technological } \\
\text { (TEC) }\end{array}$ \\
\hline
\end{tabular}

Figure 2. Risk Breakdown Structure used in the focus groups.

The results obtained were contrasted days later with the five project managers of each project, who had also taken part in the workshops, in an open-ended interview. The project managers were asked if they agreed with the results and if there was anything that surprised them. They were also asked to identify their projects' priorities (scope, cost, scheduling, or safety), which helped give weight to and define the risk importance formula used for each project.

Finally, the results of the workshops were first analyzed qualitatively and second analyzed using the fuzzy methodology. 
To verify the RQ2 mentioned in the previous section and evaluate the link between risk management and project success (in its double dimension) in the context of international development, the following propositions are posed:

Proposition 1 (P1). The effect of risks relative to the external environment of the project (environmental, cultural, political, and safety categories) causes an impact on the success of the project.

Proposition 2 (P2). The effect of risks relative to the internal environment of the project (project management, economic, organizational, and technological categories) causes an impact on the success of the project.

\subsection{Fuzzy Logic}

Initially, fuzzy logic was applied exclusively in the field of formal sciences (e.g., mathematics, statistics, or logic). With the first works known to apply this technique carried out by Zadeh [61], fuzzy logic was considered a mathematical theory used under multipurpose logic. In more recent years, the approach has been applied to several areas such as for the identification of stakeholders [62], transportation [63,64], and energy [65]. It has also been applied in the area of sustainability in examining the effects of climate change [66] and capacity factors and their influence on project results in developing countries [67]. In recent years, its use has also spread in the field of international development, establishing as a very useful methodology for measuring the use of project management tools in NGDOs [68]. Its application in this field of international development fits in with the fact that is particularly appropriate for uncertain environments $[61,63,66,68]$, since when classifying membership in a category, an all or nothing approach is not used, as diffuse logic recognizes the possibility of belonging to more than one, allowing for the development of gradual scales in regard to perceptions, as in this case for risks that affect a project and its success.

In the present research, fuzzy logic is used, employing fsQCA 3.0 software (fuzzy set Qualitative Comparative Analysis). This program uses combinatorial logic, fuzzy logic set theory, and Boolean minimization to determine which combinations of features may be necessary or sufficient to give a certain result [69]. FsQCA identifies necessary conditions and their effects when obtaining a result or output variable. The method also allows for the identification of sufficient conditions (a combination of conditions) from which to achieve a result [70].

To introduce the data into fsQCA, it is necessary to define the variables, which in our case are risk categories (input variables or conditions) and levels of project success in impact and PM (output variables or outcomes). These conditions and outcomes are studied across 31 people or cases representing the total number of participants in the five workshops.

The input variables (conditions) are obtained from the total values given by each person (case) for each category. That is, each person's overall score for each category is the sum of all scores obtained on the importance of each form of risk within a given category. The importance of each form of risk is determined by the product of the probability of a risk's manifestation and its impact. As impact was previously divided into corresponding impacts on scheduling, costs, scope, and safety (see Appendix A), final impact values were obtained from weights estimated by the project manager of each project.

As for each project, a different number of risks was identified, and the value obtained for each category of risk varies not only by scores given (perceptions of risk) but also by the number of risks identified. This variation was addressed through data calibration, and the importance of eight types of risk corresponding to the 31 participants from the five projects was measured, forming our conditions. Each participant also scored levels of project success in terms of impacts on the beneficiary population and project management on a scale of 1 to 10 as outcomes. An outline of our cases, conditions, and outcomes are given in Figure 3. 


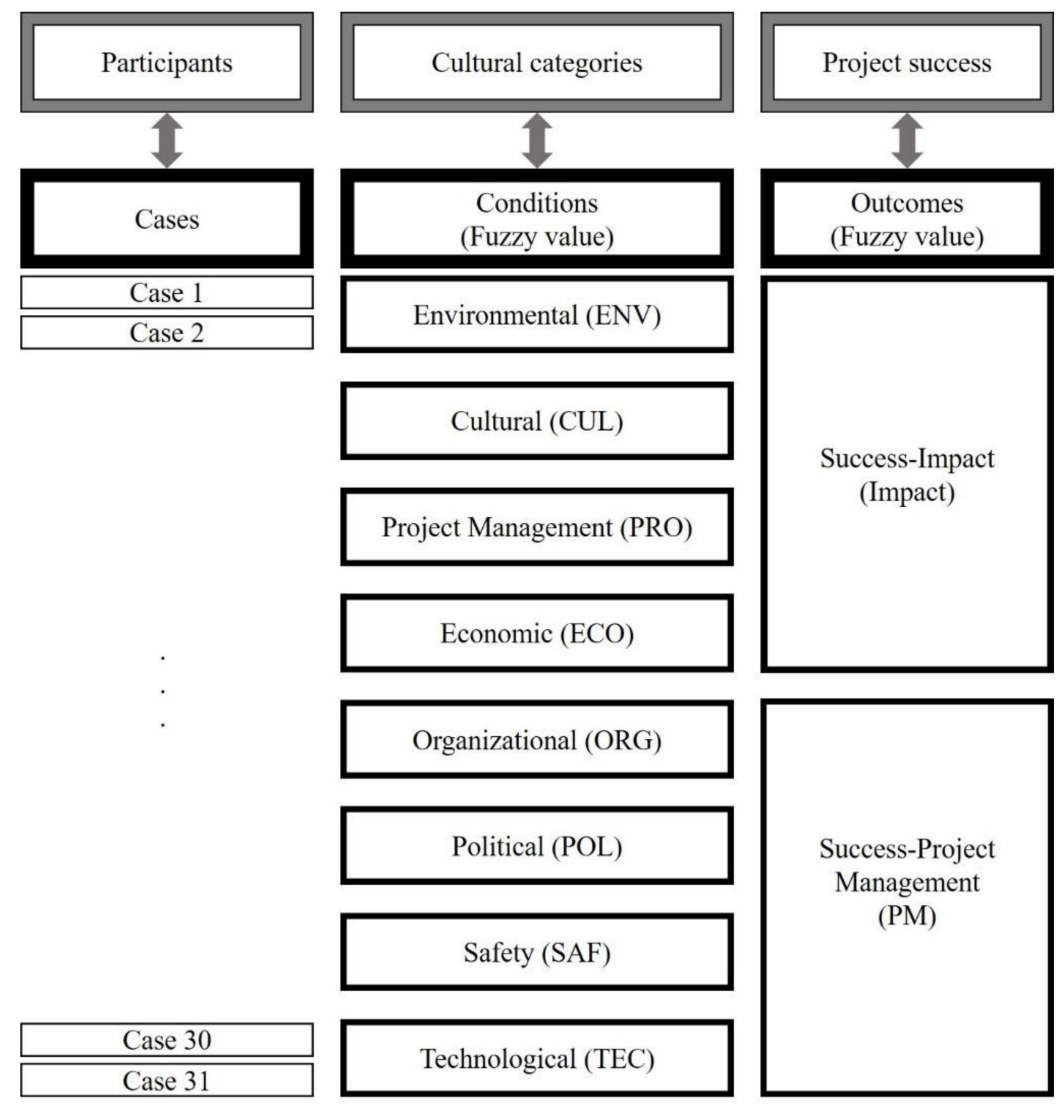

Figure 3. Cases, conditions, and results used for the study.

The data used in the fsQCA analysis are shown in Table 2.

Table 2. Workshop data used for the analysis.

\begin{tabular}{ccccccccccc}
\hline \multirow{2}{*}{ Cases } & ENV & CUL & PRO & ECO & ORG & POL & SAF & TEC & Impact & PM \\
\hline Par1 & 6 & 49.4 & 5.6 & 36 & 119.2 & 27.8 & 19 & 21.6 & 8.5 & 9 \\
Par2 & 7.2 & 64.4 & 10.2 & 30.8 & 79.6 & 24.2 & 16.8 & 33 & 7.5 & 8 \\
Par3 & 1.8 & 40 & 14.6 & 29.4 & 87.2 & 32.4 & 8.8 & 9.8 & 9.5 & 9 \\
Par4 & 1.2 & 62.4 & 16.6 & 32.4 & 135.4 & 28.8 & 10.8 & 12.2 & 7.5 & 10 \\
Par5 & 1.4 & 52.4 & 17.6 & 30 & 116.8 & 32.4 & 7.8 & 13.2 & 8.5 & 10 \\
Par6 & 11.2 & 62 & 24.8 & 42 & 115.6 & 30.6 & 0 & 15 & 9.5 & 9 \\
Par7 & 6.6 & 70.4 & 42.4 & 41.2 & 181 & 21.6 & 28.6 & 32.6 & 8.5 & 9 \\
Par8 & 4 & 41.8 & 77.4 & 68.4 & 25.8 & 69.8 & 13.6 & 13.2 & 6 & 6 \\
Par9 & 12 & 47.2 & 59 & 96.8 & 42 & 88.8 & 41.4 & 39.2 & 6.5 & 8 \\
Par10 & 4.8 & 51.8 & 41.6 & 46.2 & 21.4 & 47.4 & 20.4 & 14.8 & 7.5 & 8 \\
Par11 & 9 & 52.2 & 85.8 & 88.2 & 74.6 & 47.6 & 24.4 & 43.4 & 7.5 & 7 \\
Par12 & 12.4 & 59.4 & 28 & 20 & 68.2 & 43.6 & 9 & 16.4 & 6 & 5 \\
Par13 & 6.4 & 27.2 & 12 & 22.6 & 33 & 26.4 & 14.4 & 12.2 & 6.7 & 5 \\
Par14 & 41.8 & 77.2 & 51 & 4.8 & 69.8 & 48.6 & 16 & 26 & 10 & 10 \\
Par15 & 52.4 & 159.2 & 97.6 & 122.4 & 150.4 & 40.2 & 51.6 & 58.8 & 5.5 & 6 \\
Par16 & 17.6 & 86.6 & 33.4 & 86.4 & 71.8 & 45.2 & 60 & 25.2 & 6.5 & 6 \\
Par17 & 28.4 & 113.4 & 35.2 & 51.4 & 84 & 52.6 & 28.8 & 35.4 & 5 & 5 \\
Par18 & 32 & 116 & 56.8 & 103.4 & 118.4 & 54.4 & 32 & 31.2 & 7.5 & 6 \\
Par19 & 23 & 181.2 & 57.2 & 155 & 70.3 & 66 & 8 & 24 & 5.5 & 7 \\
Par20 & 26 & 128.8 & 36.6 & 83.4 & 71.2 & 14.4 & 35.2 & 52.4 & 7 & 8 \\
\hline
\end{tabular}


Table 2. Cont.

\begin{tabular}{ccccccccccc}
\hline \multirow{2}{*}{ Cases } & & \multicolumn{9}{c}{ Categories } \\
& & CUL & PRO & ECO & ORG & POL & SAF & TEC & Results \\
Impact & PM \\
\hline Par21 & 32.4 & 151.4 & 35.6 & 53.6 & 81.6 & 54 & 27.6 & 28.2 & 7 & 7 \\
Par22 & 57.2 & 119.2 & 96 & 93.6 & 80 & 61 & 34.4 & 55 & 6 & 6 \\
Par23 & 6.2 & 62.8 & 21.8 & 41.6 & 47 & 7.6 & 5.2 & 7 & 6.3 & 6.5 \\
Par24 & 15.8 & 78 & 19 & 31.6 & 24.8 & 19.4 & 3 & 6 & 6 & 7 \\
Par25 & 30 & 59.4 & 9.2 & 43.2 & 57 & 35 & 4.8 & 10 & 6.5 & 6 \\
Par26 & 30.8 & 128 & 75.6 & 92 & 130.6 & 61.8 & 61 & 19.6 & 6.5 & 6 \\
Par27 & 23.8 & 131.8 & 26 & 73.4 & 77.2 & 49.4 & 12.4 & 17.6 & 6.5 & 9 \\
Par28 & 12 & 26.8 & 6.8 & 56.6 & 62.55 & 26.8 & 8.6 & 6.8 & 8 & 9 \\
Par29 & 2.3 & 104.8 & 42.4 & 50 & 99.5 & 19.2 & 48.5 & 42 & 6 & 8 \\
Par30 & 2.2 & 101 & 41.3 & 51 & 96.75 & 19 & 47.5 & 43 & 7.5 & 9 \\
Par31 & 10.8 & 75.6 & 37.5 & 51.8 & 85.5 & 58.5 & 22 & 23.4 & 7.5 & 6 \\
\hline
\end{tabular}

\section{Results}

\subsection{Qualitative Analysis to Identify and Assess Risks and Success}

The five most important project risks identified from the focus groups are described in Table 3.

Table 3. Description of the five most important risks facing each project.

\begin{tabular}{|c|c|c|}
\hline $\begin{array}{c}\text { Id. } \\
\text { Project }\end{array}$ & Id. Risk & Risk Description \\
\hline \multirow{5}{*}{ P1 } & P1.ECO.1 & Inability to cope with transportation costs to attend training \\
\hline & P1.POL.1 & Removal of project support due to a change of government \\
\hline & P1.ECO.2 & Delays in financing from the donor \\
\hline & P1.CUL.1 & Difficulties asking questions of beneficiaries \\
\hline & P1.CUL.2 & Greater participation in sports activities (opportunity) \\
\hline \multirow{5}{*}{$\mathrm{P} 2$} & P2.ECO.2 & Budget delays \\
\hline & P2.ECO.6 & Lack of interest among investors to co-finance business plans of entrepreneurs \\
\hline & P2.POL.5 & $\begin{array}{c}\text { Lack of interest among local governments to measure impacts of } \\
\text { cultural industries }\end{array}$ \\
\hline & P2.POL.2 & Lack of collaboration from public institutions in facilitating cultural heritage \\
\hline & P2.CUL.4 & Communication difficulties between beneficiaries and the project team \\
\hline \multirow{5}{*}{ P3 } & P3.CUL.1 & Fears of facing new production challenges \\
\hline & P3.POL.1 & Lack of interest from local governments to access economic impacts \\
\hline & P3.POL.2 & Lack of local government support \\
\hline & P3.PRO.2 & Inexperience of the project manager across similar projects \\
\hline & P3.SAF.2 & Displacement through conflict zones to carry out training \\
\hline \multirow{5}{*}{ P4 } & P4.ECO.1 & Sale price fluctuations \\
\hline & P4.CUL.1 & Communication difficulties between female beneficiaries \\
\hline & P4.POL.1 & Existence of political interests when selecting productive activities \\
\hline & P4.CUL.2 & Resistance to collaborative associative work \\
\hline & P4.CUL.3 & Dependence on permission from husbands or parents to participate \\
\hline \multirow{5}{*}{ P5 } & P5.ECO.1 & Difficulties with administrative purchasing management \\
\hline & P5.CUL.1 & Difficulties from the project team with communicating with beneficiaries \\
\hline & P5.POL.1 & Lack of collaboration with public institutions \\
\hline & P5.CUL.2 & Lack of participation from beneficiaries without orders from superiors \\
\hline & P5.CUL.3 & Dependence on the leadership of specific people \\
\hline
\end{tabular}

Table 4 presents the most relevant values derived from the qualitative analysis. Values in this table were obtained from Appendix A and by translating the qualitative scale for probability and impact into a scale of 1 to 5 . Risk importance is measured as the product of probability and impact and weighted accordingly. 
Table 4. Summary of the qualitative analysis.

\begin{tabular}{|c|c|c|c|c|c|c|c|c|c|c|}
\hline Id. Project & \multicolumn{2}{|c|}{ P1 } & \multicolumn{2}{|c|}{ P2 } & \multicolumn{2}{|c|}{ P3 } & \multicolumn{2}{|c|}{ P4 } & \multicolumn{2}{|c|}{ P5 } \\
\hline $\begin{array}{l}\text { Participants } \\
\text { (focus group) }\end{array}$ & \multicolumn{2}{|c|}{7} & \multicolumn{2}{|c|}{4} & \multicolumn{2}{|c|}{3} & \multicolumn{2}{|c|}{13} & \multicolumn{2}{|c|}{4} \\
\hline $\mathrm{N}^{\mathrm{o}}$ Risks & \multicolumn{2}{|c|}{33} & \multicolumn{2}{|c|}{35} & \multicolumn{2}{|c|}{28} & \multicolumn{2}{|c|}{45} & \multicolumn{2}{|c|}{51} \\
\hline \multirow{6}{*}{$\begin{array}{c}\text { Top } 5 \text { Risks and } \\
\text { their } \\
\text { Importance }\end{array}$} & Id. Risk & Imp. & Id. Risk & Imp. & Id. Risk & Imp. & Id. Risk & Imp. & Id. Risk & Imp. \\
\hline & P1.ECO.1 & 18.2 & P2.ECO. 2 & 16.6 & P3.CUL.1 & 24 & P4.ECO.1 & 13.6 & P5.ECO.1 & 15 \\
\hline & P1.POL.1 & 15.8 & P2.ECO.6 & 14.9 & P3.POL.1 & 14.7 & P4.CUL.1 & 13.5 & P5.CUL.1 & 14.4 \\
\hline & P1.ECO.2 & 15.8 & P2.POL.5 & 13.5 & P3.POL. 2 & 13.1 & P4.POL.1 & 13.4 & P5.POL.1 & 14.2 \\
\hline & P1.CUL.1 & 15.6 & P2.POL.2 & 13.1 & P3.PRO. 2 & 12 & P4.CUL.2 & 12.8 & P5.CUL.2 & 14.1 \\
\hline & P1.CUL.2 & 14.8 & P2.CUL.4 & 12.8 & P3.SAF.2 & 12 & P4.CUL.3 & 12.6 & P5.CUL.3 & 13.6 \\
\hline Priority & \multicolumn{2}{|c|}{ Scope } & \multicolumn{2}{|c|}{ Scope } & \multicolumn{2}{|c|}{ Scope } & \multicolumn{2}{|c|}{ Scope } & \multicolumn{2}{|c|}{ Schedule } \\
\hline \multirow{2}{*}{ Success } & Impact & PM & Impact & PM & Impact & PM & Impact & PM & Impact & PM \\
\hline & 8.5 & 9.1 & 6.8 & 7.3 & 7.6 & 6.7 & 6.3 & 6.6 & 7.3 & 8 \\
\hline
\end{tabular}

Table 4 shows that among the most important risks common to all projects, those associated with the economic (ECO), cultural (CUL), and political (POL) categories stand out. These common and significant risks include a lack of support and/or interest from local governments, financing delays, and communication difficulties between the beneficiary community and project team. It should be noted that problems with communication are not in most cases related to language barriers but to cultural patterns linked to hierarchical structures whereby conversation only flows between people of the same hierarchy, which is important to consider in relation to the participatory methodologies used in these types of projects.

Risks related to technologies, from the results obtained, are not a priority for any of the projects. It is more difficult to manage relationships between people and institutions than those with equipment and technology. Similarly, while the Department of Cauca is located in a mountainous area subject to heavy rains and landslides, risks related to environmental phenomena are not those that most affect the projects despite many of them being related to agricultural production. Additionally, despite insecurity present in Cauca, safety risks are hardly seen as crucial among local teams.

While in the workshops the participants were asked to identify positive risks (opportunities), only the higher education project (P1) identified such risks as shown in Table 3, and they appear among the five most important. The methodology of strategic foresight applied to this project surely contributed to the search for opportunities in this project on which an in-depth investigation has been completed [71].

In terms of priorities, meeting the project scope is paramount to almost all of the projects, which involves a desire to deliver all planned activities and to reach as many people as possible.

Finally, regarding levels of success achieved, while the teams prioritize success in impact, success in project management shows higher scores, though not for the entrepreneurial project for displaced populations (P3), which also shows the greatest variations between measures of success. The highest success scores both for impact and PM are reached by the higher education project (P1), despite this project being run by a newer team.

\subsection{Quantitative Analysis to Identify Links between Risk Management and Success Levels}

The relationship between IDP success in Cauca and the management of risks faced is studied using fuzzy logic for several reasons. First, given the small sample size, fuzzy logic can serve as a very interesting alternative to traditional statistical methods. Second, the use of this methodology is highly recommended when one can intuit possible causal structures and their complexities and different options, which requires having excellent knowledge of the cases studied [69]. Finally, we study 31 cases corresponding to assessments of success and risk made by 31 people working on the projects analyzed. According to Kent and Olsen [69], the ideal number of cases for fsQCA 3.0 fuzzy logic analysis is 
roughly 30, meaning that both the method and program used are considered adequate for this analysis, as other social science research studies with small samples have already shown [72].

Once the cases are defined (sample of 31 people), conditions (risk categories), outcomes (levels of project success in impact and PM), and the variables (conditions and outcomes) were calibrated. Calibration involves transforming conventional variables into diffuse variables as conditions (input variables) and outcomes (output variables). This calibration determines the degree to which cases belong to each set with scores of 0 to 1 . Among the calibrations proposed by Ragin [73], three values $(0.3 ; 0.6 ; 0.9)$ were chosen. Table 5 shows the meaning of these calibrations. Table 6 shows the data after calibration to be analyzed by fsQCA.

Table 5. Calibration with four sets [60].

\begin{tabular}{cc}
\hline Value of the Calibrated Case & Interpretation \\
\hline$<0.3$ & The case has a minimum membership to the condition \\
$0.3-0.6$ & The case has a medium-low membership to the condition \\
$0.6-0.9$ & The case has an upper-middle belonging to the condition \\
$>0.9$ & The case has a maximum belonging to the condition \\
\hline
\end{tabular}

Table 6. Calibrated data for analysis.

\begin{tabular}{|c|c|c|c|c|c|c|c|c|c|c|}
\hline \multirow{2}{*}{ Cases } & \multicolumn{8}{|c|}{ Conditions } & \multicolumn{2}{|c|}{ Outcomes } \\
\hline & ENV & CUL & PRO & ECO & ORG & POL & SAF & TEC & Impact & PM \\
\hline Par1 & 0.3 & 0.3 & 0.3 & 03 & 0.9 & 0.6 & 0.6 & 0.6 & 0.9 & 0.9 \\
\hline Par2 & 0.3 & 0.6 & 0.3 & 0.3 & 0.6 & 0.3 & 0.6 & 0.9 & 0.6 & 0.6 \\
\hline Par3 & 0.3 & 0.3 & 0.3 & 0.3 & 0.6 & 0.6 & 0.3 & 0.3 & 0.9 & 0.9 \\
\hline Par4 & 0.3 & 0.6 & 0.3 & 0.3 & 0.9 & 0.6 & 0.6 & 0.3 & 0.6 & 0.9 \\
\hline Par5 & 0.3 & 0.6 & 0.3 & 0.3 & 0.9 & 0.6 & 0.3 & 0.3 & 0.9 & 0.9 \\
\hline Par6 & 0.6 & 0.6 & 0.6 & 0.6 & 0.9 & 0.6 & 0.3 & 0.6 & 0.9 & 0.9 \\
\hline Par7 & 0.3 & 0.6 & 0.6 & 0.6 & 0.9 & 0.3 & 0.6 & 0.9 & 0.9 & 0.9 \\
\hline Par8 & 0.3 & 0.3 & 0.9 & 0.6 & 0.3 & 0.9 & 0.6 & 0.3 & 0.3 & 0.3 \\
\hline Par9 & 0.6 & 0.3 & 0.9 & 0.9 & 0.3 & 0.9 & 0.9 & 0.9 & 0.3 & 0.6 \\
\hline Par10 & 0.3 & 0.6 & 0.6 & 0.6 & 0.3 & 0.6 & 0.6 & 0.3 & 0.6 & 0.6 \\
\hline Par11 & 0.3 & 0.6 & 0.9 & 0.9 & 0.6 & 0.6 & 0.6 & 0.9 & 0.6 & 0.6 \\
\hline Par12 & 0.6 & 0.6 & 0.6 & 0.3 & 0.6 & 0.6 & 0.3 & 0.6 & 0.3 & 0.3 \\
\hline Par13 & 0.3 & 0.3 & 0.3 & 0.3 & 0.3 & 0.6 & 0.6 & 0.3 & 0.3 & 0.3 \\
\hline Par14 & 0.9 & 0.6 & 0.9 & 0.3 & 0.6 & 0.6 & 0.6 & 0.6 & 0.9 & 0.9 \\
\hline Par15 & 0.9 & 0.9 & 0.9 & 0.9 & 0.9 & 0.6 & 0.9 & 0.9 & 0.3 & 0.3 \\
\hline Par16 & 0.6 & 0.6 & 0.6 & 0.9 & 0.6 & 0.6 & 0.9 & 0.6 & 0.3 & 0.3 \\
\hline Par17 & 0.6 & 0.9 & 0.6 & 0.6 & 0.6 & 0.9 & 0.6 & 0.9 & 0.3 & 0.3 \\
\hline Par18 & 0.9 & 0.9 & 0.9 & 0.9 & 0.9 & 0.9 & 0.9 & 0.9 & 0.6 & 0.3 \\
\hline Par19 & 0.6 & 0.9 & 0.9 & 0.9 & 0.6 & 0.9 & 0.3 & 0.6 & 0.3 & 0.6 \\
\hline Par20 & 0.6 & 0.9 & 0.6 & 0.9 & 0.6 & 0.3 & 0.9 & 0.9 & 0.6 & 0.6 \\
\hline Par21 & 0.9 & 0.9 & 0.6 & 0.6 & 0.6 & 0.9 & 0.6 & 0.6 & 0.6 & 0.6 \\
\hline Par22 & 0.9 & 0.9 & 0.9 & 0.9 & 0.6 & 0.9 & 0.9 & 0.9 & 0.3 & 0.3 \\
\hline Par23 & 0.3 & 0.6 & 0.6 & 0.6 & 0.3 & 0.3 & 0.3 & 0.3 & 0.3 & 0.3 \\
\hline Par24 & 0.6 & 0.6 & 0.3 & 0.3 & 0.3 & 0.3 & 0.3 & 0.3 & 0.3 & 0.6 \\
\hline Par25 & 0.9 & 0.6 & 0.3 & 0.6 & 0.6 & 0.6 & 0.3 & 0.3 & 0.3 & 0.3 \\
\hline Par26 & 0.9 & 0.9 & 0.9 & 0.9 & 0.9 & 0.9 & 0.9 & 0.6 & 0.3 & 0.3 \\
\hline Par27 & 0.6 & 0.9 & 0.6 & 0.6 & 0.6 & 0.6 & 0.6 & 0.6 & 0.3 & 0.9 \\
\hline Par28 & 0.6 & 0.3 & 0.3 & 0.6 & 0.6 & 0.6 & 0.3 & 0.3 & 0.9 & 0.9 \\
\hline Par29 & 0.3 & 0.9 & 0.6 & 0.6 & 0.6 & 0.3 & 0.9 & 0.9 & 0.3 & 0.6 \\
\hline Par30 & 0.3 & 0.9 & 0.6 & 0.6 & 0.6 & 0.3 & 0.9 & 0.9 & 0.6 & 0.9 \\
\hline Par31 & 0,6 & 0.6 & 0.6 & 0.6 & 0.6 & 0.9 & 0.6 & 0.6 & 0.6 & 0.3 \\
\hline
\end{tabular}

A truth table with fuzzy scores of variables was used to conduct an analysis of necessary and sufficient conditions using fsQCA. 
Necessary conditions were first analyzed. The need for a condition is demonstrated by a result forming a subset of a condition (i.e., the degree of relevance to an outcome must be less than or equal to that of the condition), [64,70]. For this purpose, values obtained for each outcome (Impact, PM) and each absence version ( Impact, $\sim \mathrm{DP})$ are analyzed together with the presence of conditions (ENV, CUL, PRO, ECO, ORG, POL, SAF, and TEC) and their absence ( ENV, CCUL, PRO, $\sim \mathrm{ECO}, \sim \mathrm{ORG}, \sim \mathrm{POL}$, $\sim \mathrm{SAF}$, and $\sim \mathrm{TEC})$.

According to Ragin [66], a condition is necessary when it has a consistency index of greater than 0.9. Table 7 shows the values obtained with fsQCA. Attending to these numbers, the values of consistency with greater relevance are taken (in bold), although in some cases they are not superior to the indicative value of 0.9 .

Table 7. Necessary conditions.

\begin{tabular}{|c|c|c|c|c|c|c|c|c|}
\hline Condition & $\begin{array}{r}\text { Impa } \\
\text { Consistency }\end{array}$ & $\begin{array}{l}\text { act } \\
\text { Coverage }\end{array}$ & $\begin{array}{r}\sim \operatorname{Imp} \\
\text { Consistency }\end{array}$ & $\begin{array}{l}\text { act } \\
\text { Coverage }\end{array}$ & $\begin{array}{r}\text { PM } \\
\text { Consistency } \\
\end{array}$ & Coverage & $\begin{array}{r}\sim \mathrm{PN} \\
\text { Consistency }\end{array}$ & Coverage \\
\hline ENV & 0.722 & 0.696 & 0.811 & 0.714 & 0.683 & 0.732 & 0.846 & 0.655 \\
\hline$\sim \mathrm{ENV}$ & 0.704 & 0.803 & 0.655 & 0.683 & 0.678 & 0.859 & 0.654 & 0.598 \\
\hline CUL & 0.815 & 0.657 & 0.885 & 0.652 & 0.800 & 0.716 & 0.892 & 0.577 \\
\hline$\sim$ CUL & 0.568 & 0.844 & 0.534 & 0.725 & 0.528 & 0.871 & 0.561 & 0.670 \\
\hline PRO & 0.778 & 0.677 & 0.865 & 0.688 & 0.733 & 0.709 & 0.885 & 0.618 \\
\hline$\sim \mathrm{PRO}$ & 0.642 & 0.839 & 0.594 & 0.710 & 0.605 & 0.879 & 0.585 & 0.613 \\
\hline ECO & 0.759 & 0.661 & 0.865 & 0.688 & 0.717 & 0.693 & 0.885 & 0.618 \\
\hline$\sim \mathrm{ECO}$ & 0.642 & 0.839 & 0.574 & 0.685 & 0.606 & 0.879 & 0.561 & 0.589 \\
\hline ORG & 0.926 & 0.781 & 0.804 & 0.619 & 0.867 & 0.812 & 0.838 & 0.568 \\
\hline$\sim \mathrm{ORG}$ & 0.549 & 0.754 & 0.716 & 0.898 & 0.539 & 0.822 & 0.723 & 0.797 \\
\hline POL & 0.796 & 0.672 & 0.858 & 0.661 & 0.733 & 0.687 & 0.900 & 0.609 \\
\hline$\sim \mathrm{POL}$ & 0.599 & 0.822 & 0.574 & 0.720 & 0.583 & 0.890 & 0.538 & 0.593 \\
\hline SAF & 0.796 & 0.693 & 0.838 & 0.667 & 0.750 & 0.726 & 0.861 & 0.602 \\
\hline$\sim \mathrm{SAF}$ & 0.617 & 0.806 & 0.615 & 0.734 & 0.589 & 0.855 & 0.608 & 0.637 \\
\hline TEC & 0.796 & 0.682 & 0.817 & 0.640 & 0.767 & 0.730 & 0.831 & 0.571 \\
\hline$\sim \mathrm{TEC}$ & 0.580 & 0.777 & 0.594 & 0.727 & 0.550 & 0.818 & 0.608 & 0.653 \\
\hline
\end{tabular}

The results of Table 7 show that having a high impact on a project requires the consideration of the organizational risks; it means that the project requires a good and supervised organization. It also highlights the importance given to cultural risks. Analyzing now the denied case, the absence of impact, it can be seen that a project has little impact on the beneficiaries, the condition that most influences is the culture. The fact that the risks associated with cultural differences appear both in the impact and non-impact results demonstrates the strong relationship between the risks in this category and the impact of the project on the beneficiaries.

Regarding the necessary conditions to consider that the project has been successful in the project management, there is a curious agreement on the conditions of organization and culture, although with less relevant values. When analyzing the lack of success in the PM the political condition dominates, although the culture, the economy, and the project management are also present.

After this study of necessary conditions, sufficient conditions were analyzed. Combinations of sufficient conditions are also called causal combinations. According to Schneider et al. [74], only models with a consistency level of greater than 0.75 are acceptable. While others such as Ragin [70] and Eng and Woodside [75] call for values of greater than $0.8,0.75$ is considered sufficient. Consistency refers to the level at which data subsets are present in an outcome. It is also important to highlight that from all combinations of possible conditions for any solution, the most representative is the one with greater coverage.

In the analysis of sufficient conditions, fsQCA 3.0 performs Boolean minimization that allows for three solutions: simplified, intermediate, and complex.

Based on the types of solutions in which they appear, causal conditions can be divided into core (appearing in the simplified and intermediate solutions) and contributing conditions (appearing in the intermediate solution). 
Figure 4 presents the sufficient conditions for the results with higher values of coverage and consistency. The intermediate solution was employed for the combination of sufficient conditions following previous studies $[64,70]$.

\begin{tabular}{|c|c|c|c|c|c|c|c|c|}
\hline & \multicolumn{3}{|c|}{ Success (Impact) } & \multirow{2}{*}{\begin{tabular}{|c|c|}
$\begin{array}{c}\text { Absence of success } \\
\text { (Impact) }\end{array}$ \\
2 \\
\end{tabular}} & \multicolumn{2}{|c|}{ Success (PM) } & \multicolumn{2}{|c|}{$\begin{array}{c}\text { Absence of } \\
\text { success (PM) }\end{array}$} \\
\hline Configuration No. & 9 & 7 & 8 & & 3 & 4 & 5 & 1 \\
\hline ENV & O & - & 0 & & 0 & & - & 0 \\
\hline CUL & 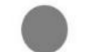 & 0 & 0 & - & - & - & 0 & \\
\hline PRO & - & - & - & - & - & - & - & - \\
\hline ECO & - & 0 & - & 0 & - & $\bullet$ & - & - \\
\hline ORG & - & - & - & $\bullet$ & 0 & 0 & 0 & 0 \\
\hline POL & & 0 & 0 & & & o & - & - \\
\hline SAF & - & - & - & 0 & - & - & - & - \\
\hline TEC & - & - & - & - & - & - & • & 0 \\
\hline Raw coverage & 0.512 & 0.494 & 0.481 & 0.682 & 0.517 & 0.494 & 0.4461 & 0.423 \\
\hline Unique coverage & 0.031 & 0.037 & 0.031 & 0.230 & 0.011 & 0.022 & 0.538 & 0.054 \\
\hline Consistency & 0.965 & 0.976 & 0.963 & 0.802 & 0.969 & 0.978 & 0.879 & 0.859 \\
\hline Solution coverage & & 0.75 & & 0.82 & & & & \\
\hline Solution consistency & & 0.94 & & 0.81 & & & & \\
\hline
\end{tabular}

Figure 4. Summary of conditions determined from fuzzy logic. Note: as per Fiss's [76] notation, grey circles indicate the presence of the condition, white circles indicate the absence of the condition, and large circles indicate a core condition and small circles indicate contributing conditions. Blank spaces mean that the condition is irrelevant.

All of the proposed models meet the consistency levels of greater than 0.75; thus, all of the configurations can be considered valid for the presence and absence of both outcomes.

The interpretation of Figure 4 will be done for each of the outcomes. First, for the impact of the project, it can be said that the careful management of risks associated with both culture and politics, along with avoiding all risks that may endanger the environment, greatly increases the probability of success in the impact of an IDP in the area of Cauca. Second, the presence of high risks, mainly political, economic, and safety, but without neglecting all the others (except for those related to the environment, which does not enter the equation) brings with the absence of the impact in the beneficiary community. Third, by minimizing mainly the risks related to the environment, and with proper management of all the other risks, especially the organizational ones, it would be possible to achieve success in the PM of an IDP in Cauca. Fourth and last, the presence of important risks of all categories, even with the absence of organizational and cultural risks, would result in the absence of success in the PM.

The strength of the union of necessary and sufficient conditions establishes as significant the following direct relationships: (i) there will be success in a project's impact if and only if cultural risks (CUL) are managed properly; (ii) there will be no success in a project's impact if and only if economic risks (ECO) are not managed properly; (iii) there will project management success if and only if organizational risks (ORG) are managed properly. These findings highlight the relevance of the following conditions for outcomes: cultural, economic, and organizational risks. 
These relationships are perhaps the most valuable results of this research, establishing that it is possible for an IDP to achieve successful impacts on beneficiary communities in Cauca if and only if special attention is paid to risks associated with cultural differences and to identifying and controlling them from the beginning. In the same vein, an IDP in the studied area will have no impact on the beneficiary community if and only if economic risks are not adequately addressed. Regarding the impact of a project and its absence, as political risks are also very present, these must also be addressed.

These initial results were presented to the Head of International Cooperation of the Government of Cauca for validation through an interview, from which the most relevant considerations are identified.

The interview first corroborated the finding of the importance of risks associated with cultural differences in having an impact on the community, confirming the importance of considering the ancestral culture and knowledge of an area, given that "The cultural aspect is essential. When a project does not fit with the culture, it does not work." In addition, "some indigenous communities are environmental authorities through the Indigenous Regional Council of Cauca (CRIC, by its Spanish initials) and, therefore, it's necessary to garner their support when developing any project."

Limited project impact and its relation to economic risks is especially critical "when the project is executed by several entities." Thus, "responsibilities and funds should be independent to avoid delays." Such funding delays can prevent activities from being carried out, impacting the scope of a project and potentially resulting in an IDP not having the impact initially planned in the community (lack of impact).

Likewise, the influence of political risks is highlighted because "if a project is not in the development plan, it is very difficult to articulate. Projects have to be articulated with regional development policies" and "risks associated with changes in government must be considered."

The third direct relationship identified establishes that an IDP in Cauca will succeed in its management if and only if organizational risks are identified and controlled throughout the project. The director of cooperation validated this finding and believes that "the risks that most affect an IDP are those that affect the project's own sustainability through poor organization and few alliances between the various executing organizations; these risks can be categorized as organizational."

A less significant relationship between a lack of success in project development and political, economic, and project management risks is also identified.

Finally, for a complementary validation of the summary table presented in Figure 4, the Head of Cooperation of the Cauca Government was asked why he believed that technical and security risks were not as representative and how he viewed environmental risks and conditions of their absence. He responded that "the technical part can be corrected, and the safety part is very important and can prevent many activities from developing; a project can have no impact, but this can be fixed in most cases by involving the army." Regarding the environment, he states "Nowadays it is considered universal to all projects as well as addressing gender because respect for the land is essential. Almost all IDPs in Cauca address this aspect already; maybe, even though it is very important, it is not identified as a necessary condition."

\section{Discussion}

The need to restructure international development cooperation towards a more effective model in social, economic, and environmental terms and including new actors while leaving none behind constitutes one of the most critical challenges facing society in this century.

An IDP is involved in processes of change, and any change implies uncertainty; therefore, risks are inevitable (but manageable). The best tool for combatting uncertainty is information and the best source of information is the beneficiary community.

The present work identifies a limited use of risk management among IDPs in Cauca, confirming what previous studies have already reported [71,77]. In building on other studies on the links between risk management and project success [55,60], this work establishes direct relationships between project success and the management of specific risks in international development, a sector in which 
this relationship has until now only been studied in an exploratory manner by the World Bank [5]. This confirms the research hypothesis: the success of IDP in Cauca depends on the proper management of its risks.

Through the case study of Cauca, it is possible to address the first research question through qualitative analysis and find that the most important risks common to all of the projects studied correspond to economic, cultural, and political issues.

A subsequent analysis applying fuzzy logic identifies a relationship between risk management and projects success, addressing the second research question. The results highlight the importance of identifying and managing cultural differences at the start of a project as a necessary and sufficient condition to achieve project impact. Thus, within the first proposition, among all the categories of external risks, culture is the one that gains more importance over the success in the impact of the project and should be given more attention when what is sought is a greater effect on the beneficiary community, that could also be viewed as external. In this line, Kassem et al. [60] already demonstrated the influence of the local culture of the people on the success of oil and gas projects, mainly in developing countries.

The fuzzy logic analysis also finds a direct relationship between organizational risks and success in project management. Likewise, in the second proposal on the internal risks of the project, the organizational ones have the most influence and this corresponds directly to the project management, which could also be considered internal.

In addition, IDPs in Cauca have demonstrated how risks increase when working with vulnerable populations such as displaced persons, women, and ex-combatants, making the environment and circumstances decisive as some previous works also show (e.g., Ika and Donelly [22]). Additionally, an analysis of the studied projects shows that while risks can be seen as opportunities, as Kerzner [51] established, there is still much to be done in this regard. In the present work, only a few opportunities were identified for the studied education project.

The present study shows how the careful management of certain risks associated with the cultural environment can help improve project acceptance and ownership by the beneficiary community, facilitating the achievement of a project with real impacts.

In focusing on this case study of Cauca, the present research is limited to a specific context in which cultural diversity is a major factor. Therefore, some of the results obtained may not be generalizable to other contexts. In view of this limitation, future work may extend the present work to studies of other countries.

Author Contributions: Conceptualization, R.R.-R. and I.O.-M.; methodology, R.R.-R., J.R., and I.O.-M.; software, R.R.-R, and J.R.; validation, J.R.; formal analysis, R.R-R.; investigation, R.R-R, and I.O.-M; writing-original draft preparation, R.R-R..; writing-review and editing, R.R.-R, I.O.-M., J.R., and L.B.-S.; supervision, R.R.-R, I.O.-M., J.R., and L.B.-S. All authors have read and agreed to the published version of the manuscript.

Funding: This research received no external funding.

Acknowledgments: The authors would like to thank the organizations which allow the study of their projects and the participants in the five workshops for their collaboration. Special gratitude to the head of cooperation from the Cauca Government, Pablo Pérez, for his invaluable contribution to this research.

Conflicts of Interest: The authors declare no conflict of interest. 


\section{Appendix A}

Table A1 shows the evaluation sheet used during the workshops.

Table A1. Sheet used for the risk assessment and project success evaluation

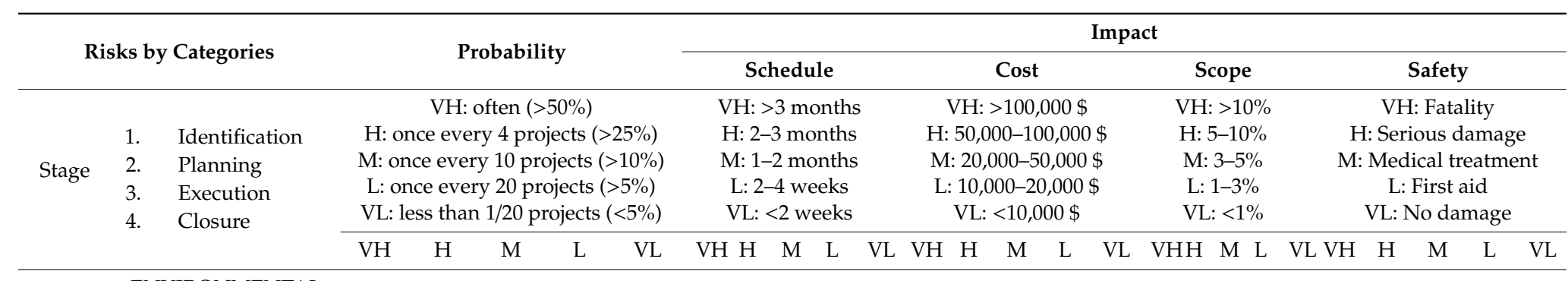

ENVIRONMENTAL

CULTURAL

PROJECT

MANAGEMENT

ECONOMIC

ORGANIZATIONAL

POLITICAL

SAFETY

TECHNOLOGICAL 


\section{References}

1. Organization for Economic Cooperation and Development (OECD). Official Development Assistance 2018. Available online: https://www2.compareyourcountry.org/oda?cr=20001\&cr1=oecd\&lg=en\&page=0 (accessed on 20 June 2020).

2. Food and Agriculture Organization of the United Nations (FAO). The State of Food Security and Nutrition in the World 2019. Safeguarding against Economic Slowdowns and Downturns; FAO: Roma, Italy, 2019.

3. Organization for Economic Cooperation and Development (OECD). Paris declaration on aid effectiveness. Available online: http://www.oecd.org/dac/effectiveness/parisdeclarationandaccraagendaforaction.htm\#: $\sim\{$ :text=\%20The \%20Paris\%20Declaration\%20outlines\%20the\%20following\%20five,Donor\%20countries \% 20coordinate\%2C\%20simplify\%20procedures\%20and...\%20More\%20 (accessed on 3 July 2020).

4. United Nations Organization (UNO). Transforming Our World: The 2030 Agenda for Sustainable Development; United Nations Organization: New York, NY, USA, 2015.

5. World Bank. Results and Performance of the World Bank Group 2017: An Independent Evaluation; World Bank: Washington, DC, USA, 2018.

6. Couillard, J.; Garon, S.; Riznic, J. The Logical Framework Approach-Millennium. Proj. Manag. J. 2009, 40, 31-44. [CrossRef]

7. Ika, L.A.; Lytvynov, V. The "Management-Per-Result" Approach to International Development Project Design. Proj. Manag. J. 2011, 42, 87-104. [CrossRef]

8. Rodríguez-Rivero, R.; Ortiz-Marcos, I.; Ballesteros-Sánchez, L.; Sánchez, M.J. Improving the management of international development projects. Int. J. Manag. Proj. Bus. 2019. [CrossRef]

9. Hekala, W. Why Donors Should Care More About Project Management. Available online: https://www.devex. com/news/why-donors-should-care-more-about-project-management-77595 (accessed on 13 June 2020).

10. Berssaneti, F.T.; Carvalho, M.M. Identification of variables that impact project success in Brazilian companies. Int. J. Proj. Manag. 2015, 33, 638-649. [CrossRef]

11. Rodríguez-Rivero, R. Metodología del Marco Lógico con Enfoque de Gestión de Riesgos para mejorar la eficacia de los Proyectos de Cooperación al Desarrollo. Ph.D. Thesis, Universidad Politécnica de Madrid, Madrid, Spain, 2019. [CrossRef]

12. Bigsten, A.; Tengstam, S. International Coordination and the Effectiveness of Aid. World Dev. 2015, 69, 75-85. [CrossRef]

13. Easterly, W. The White Man's Burden: Why the West's Efforts to Aid the Rest Have done so Much Ill and so Little Good; The Penguin Press: New York, NY, USA, 2006.

14. Brooks, A. The End of Development. A Global History of Poverty and Development; Zed Books: London, UK, 2017.

15. Moyo, D. Dead Aid: Why Aid Is Not Working and How There Is a Better Way for Africa; D\&M Publishers, Inc.: Vancouver, BC, Canada, 2009.

16. Sachs, W. The Development Dictionary: A Guide to Knowledge as Power; Zed Books: London, UK, 1992.

17. Ziai, A. I am not a Post-Developmentalist, but ... ' The influence of Post-Development on development studies. Third World Q 2017, 38, 2719-2734. [CrossRef]

18. Kates, R.W. What kind of science is sustainability science? Proc. Natl. Acad. Sci. USA 2011, 108, 19449-19450. [CrossRef] [PubMed]

19. Radcliffe, S.A. Tackling Complex Inequalities and Ecuador's Buen Vivir: Leaving No-one Behind and Equality in Diversity. Bull. Lat. Am. Res. 2018, 37, 417-433. [CrossRef]

20. Hirschman, A.O. Development Projects Observed; Brookings Institution: Washington, DC, USA, 1967.

21. Diallo, A.; Thuillier, D. The success of international development projects, trust and communication: An African perspective. Int. J. Proj. Manag. 2005, 23, 237-252. [CrossRef]

22. Ika, L.A.; Donnelly, J. Success conditions for international development capacity building projects. Int. J. Proj. Manag. 2017, 35, 44-63. [CrossRef]

23. Ika, L.A.; Diallo, A.; Thuillier, D. Critical success factors for World Bank projects: An empirical investigation. Int. J. Proj. Manag. 2012, 30, 105-116. [CrossRef]

24. Khang, D.B.; Moe, T.L. Success criteria and factors for international development projects: A lifecycle-based framework. Proj. Manag. J. 2008, 39, 72-84. [CrossRef] 
25. Steinford, P.; Walker, D.H.T. Critical success factors in project management globally and how they may be applied to aid projects. In Proceedings of the PMOZ Achieving Excellence-4th Annual Project Management Australia Conference, Brisbane, Australia, 28-31 August 2007.

26. Denizer, C.; Kaufmann, D.; Kraay, A. Good countries or good projects? Macro and micro correlates of World Bank project performance. J. Dev. Econ. 2013, 105, 288-302. [CrossRef]

27. El Mekaoui, A.; Tariq, R.; Baños Ramirez, O.; Méndez-Monroy, P.E. Sustainability, Sociocultural Challenges, and New Power of Capitalism for Renewable Energy Megaprojects in an Indigenous Mayan Community of Mexico. Sustainability 2020, 12, 7432. [CrossRef]

28. Grisham, W.T. International Project Management: Leadership in Complex Environments; Wiley \& Sons Publishing: Hoboken, NJ, USA, 2010.

29. Ika, L.A. Project Management for Development in Africa: Why Projects Are Failing and What Can Be Done About It. Proj. Manag. J. 2012, 43, 27-41. [CrossRef]

30. Ika, L.A.; Hodgson, D. Learning from international development projects: Blending Critical Project Studies and Critical Development Studies. Int. J. Proj. Manag. 2014, 32, 1182-1196. [CrossRef]

31. Boni Aristizábal, A.; Calabuig Tormo, C.; Cuesta Fernández, I.; Gómez-Torres, M.; Lozano Aguilar, J.F.; Monzó Balbuena, J.M.; Torres Martínez, A.J. La Cooperación Internacional para el Desarrollo. Cuadernos para el Desarrollo; Universitat Politècnica de València: Valencia, Spain, 2010; Volume 1.

32. LenCD. Learning Network on Capacity Development. 2020. Available online: http://lencd.org/learning/thecore-concept/capacity-development (accessed on 15 September 2020).

33. McEvoy, P.; Brady, M.; Munck, R. Capacity development through international projects: A complex adaptive systems perspective. Int. J. Manag. Proj. Bus. 2016, 9, 528-545. [CrossRef]

34. Jaramillo-Echeverri, J.; Meisel-Roca, A.; Ramírez-Giraldo, M.T. More than 100 years of improvements in living standards: The case of Colombia. Cliometrica 2019, 13, 323-366. [CrossRef]

35. CIA. The world factbook. Available online: https://www.cia.gov/library/publications/the-world-factbook/ geos/co.html (accessed on 15 June 2020).

36. International Coffee Organization (ICO). International Coffee Organization Monthly Coffee Market Report-December 2019. Available online: http://www.ico.org/Market-Report-19-20-e.asp (accessed on 27 May 2020).

37. United Nations Development Programme (UNDP). Human Development Report 2019. Beyond Income, Beyond Averages, Beyond Today: Inequalities in Human Development in the 21st Century; United Nations Development Programme: New York, NY, USA, 2019.

38. United Nations High Commissioner for Refugees (UNHCR). Global Trends. Forced Displacement in 2015; UNHCR: Geneva, Switzerland, 2016.

39. Franco, I.B.; Puppin de Oliveira, J.A.; Ali, S.H. Peace with Hunger: Colombia's Checkered Experience with Post-Conflict Sustainable Community Development in Emerald-Mining Regions. Sustainability 2018, $10,504$. [CrossRef]

40. González-Salazar, M.A.; Venturini, M.; Poganietz, W.R.; Finkenrath, M.; Leal, M.R.L.V. Combining an accelerated deployment of bioenergy and land use strategies: Review and insights for a post-conflict scenario in Colombia. Renew. Sust. Energ. Rev. 2017, 73, 159-177. [CrossRef]

41. Nail, S. Memory and resilience: A two-pronged approach to natural spaces in Colombia's transition to a peaceful society. Urban For. Urban Green. 2018, 31, 48-55. [CrossRef]

42. United Nations Office for the Coordination of Humanitarian Affairs (OCHA). Global Humanitarian Overview 2019; OCHA: Geneva, Switzerland, 2018.

43. DANE. Monetary and Multidimensional Poverty in Colombia 2018. Available online: https://www.dane.gov. co/ (accessed on 3 June 2020).

44. United Nations Development Programme (UNDP). Cauca, Main Objectives and Challenges for Sustainable Development; UNDP: Bogotá, Colombia, 2019.

45. Ministry of Education of Colombia. Enrollment Data 2018. Available online: https://www.mineducacion.gov. co (accessed on 5 May 2020).

46. Landoni, P.; Corti, B. The management of international development projects: Moving toward a standard approach or differentiation? Proj. Manag. J. 2011, 42, 45-61. [CrossRef] 
47. Cobo, J.R. Diseño de un Modelo Basado en Competencias Para la Dirección de Programas y Proyectos en el Nuevo Marco de la Cooperación Internacional Para el Desarrollo. Ph.D. Thesis, Universidad Politécnica de Madrid, Madrid, Spain, 2010.

48. Ortiz-Marcos, I.; Cobo Benita, J.R.; Aldeanueva, C.M.; Colsa, A.U. Competency training for managing international cooperation engineering projects. Proj. Manag. J. 2013, 44, 88-97. [CrossRef]

49. Kealey, D.J.; Protheroe, D.R.; MacDonald, D.; Vulpe, T. Re-examining the role of training in contributing to international project success: A literature review and an outline of a new model training program. Int. J. Intercult. Rel. 2005, 29, 289-316. [CrossRef]

50. Rodríguez-Rivero, R.; Ortiz-Marcos, I.; Ballesteros-Sánchez, L.; Romero, J. The opportunity to improve psychological competences of project managers in international business. Psychol. Mark. 2018, 35, 150-159. [CrossRef]

51. Kerzner, H. Project Management: A Systems Approach to Planning, Scheduling, and Controlling, 12th ed.; John Wiley \& Sons, Inc.: Hoboken, NJ, USA, 2017.

52. Olechoswski, A.; Oehmen, J.; Seering, W.; Ben-Daya, M. The professionalization of risk management: What role can the ISO 31000 risk management principles play? Int. J. Proj. Manag. 2016, 20, 1568-1578. [CrossRef]

53. Zwikael, O.; Ahn, M. The Effectiveness of Risk Management: An Analysis of Project Risk Planning across Industries and Countries. Risk Anal. 2011, 31, 25-37. [CrossRef]

54. De Bakker, K.; Boonstra, A.; Wortmann, H. Does Risk Management Contribute to IT Project Success? A Meta-analysis of Empirical Evidence. Int. J. Proj. Manag. 2010, 28, 493-503. [CrossRef]

55. Carvalho, M.M.; Rabechini, R. Impact of risk management on project performance: The importance of soft skills. Int. J. Prod. Res. 2015, 53, 321-340. [CrossRef]

56. Mishra, A.; Das, S.R.; Murray, J.J. Risk, process maturity, and project performance: An empirical analysis of US federal government technology projects. Prod. Oper. Manag. 2016, 25, 210-232. [CrossRef]

57. Wang, J.; Lin, W.; Huang, Y.H. A performance-oriented risk management framework for innovative R\&D projects. Technovation 2010, 30, 601-611. [CrossRef]

58. O'Connor, G.C.; Ravichandran, T.; Robeson, D. Risk management through learning: Management practices for radical innovation success. J. High Technol. Manag. Res. 2008, 19, 70-82. [CrossRef]

59. Papanikolaou, M.; Xenedis, Y. Risk-Informed performance assessment of construction projects. Sustainability 2020, 12, 5321. [CrossRef]

60. Kassem, M.A.; Khoiry, M.A.; Hamzah, N. Assessment of the effect of external risk factors on the success of an oil and gas construction project. Eng. Constr. Archit. Manag. 2020, 27, 2767-2793. [CrossRef]

61. Zadeh, L.A. Fuzzy sets. Inform. Control. 1965, 8, 338-353. [CrossRef]

62. Gil-Lafuente, A.M.; Paula, L.B. Algorithm applied in the identification of stakeholders. Kybernetes 2013, 42, 674-685. [CrossRef]

63. Paula, L.B.; Silva Marins, F.A. Algorithms applied in decision-making for sustainable transport. J. Clean. Prod. 2018, 176, 1133-1143. [CrossRef]

64. Romero Ruiz, J.J. Identificación de Los Elementos Clave de la Estrategia Competitiva en El Modelo de Negocio Aeroportuario en Un Contexto Liberalizado de Competencia Internacional: Aplicación Al Caso Del Reino Unido. Ph.D. Thesis, Universidad Politécnica de Madrid, Madrid, Spain, 2017. [CrossRef]

65. Yu, H.K.; Huang, M.C.; Huarng, K.H. Causal complexity of economic development by energy consumption. J. Bus. Res. 2016, 69, 2271-2276. [CrossRef]

66. Jones, M.C.; Cheung, W.W.L. Using fuzzy logic to determine the vulnerability of marine species to climate change. Glob. Change Biol. 2017, 24, 719-731. [CrossRef]

67. An, Y.; Garvin, M.J.; Hall, R.P. Pathways to better project delivery: The link between capacity factors and urban infrastructure projects in India. World Dev. 2017, 94, 393-405. [CrossRef]

68. Verga Matos, P.; Romao, M.; Miranda Sarmento, J.; Abaladas, A. The adoption of project management methodologies and tools by NGDOs: A mixed methods perspective. J. Bus. Res. 2019, 101, 654-659. [CrossRef]

69. Kent, R.; Olsen, W. Using fsQCA A Brief Guide and Workshop for Fuzzy-Set Qualitative Comparative Analysis; University of Stirling: Stirling, Scotland, 2008.

70. Ragin, C.C. Redesigning Social Inquiry: Fuzzy Sets and Beyond; University of Chicago Press: Chicago, IL, USA, 2008. 
71. Rodríguez-Rivero, R.; Ortiz-Marcos, I.; Diaz-Barcos, V.; Lozano Niño, S.A. Applying the Strategic Prospective Approach to Project Management in a Development Project in Colombia. Int. J. Proj. Manag. 2020. [CrossRef]

72. Roig-Tierno, N.; Huarng, K.H.; Ribeiro-Soriano, D. Qualitative comparative analysis: Crisp and fuzzy sets in business and management. J. Bus. Res. 2016, 69, 1261-1264. [CrossRef]

73. Ragin, C.C. Qualitative Comparative Analysis Using Fuzzy Sets (fsQCA); Sage: Thousand Oaks, CA, USA, 2009; pp. 87-122.

74. Schneider, C.Q.; Wagemann, C. Set-Theoretic Methods for the Social Sciences. A guide to Qualitative Comparative Analysis; Cambridge University Press: Cambridge, UK, 2010. [CrossRef]

75. Eng, S.; Woodside, A.G. Configural analysis of the drinking man: Fuzzy-set qualitative comparative analyses. Addict. Behav. 2012, 37, 541-543. [CrossRef] [PubMed]

76. Fiss, P.C. Buildig better causal theories: A fuzzy set approach to typologies in organization research. Acad. Manage. J. 2011, 54. [CrossRef]

77. Enyinda, C.I. Quantitative Risk Analysis for International Project Management and Programs in an Emerging Economy. In Leadership, Innovation and Entrepreneurship as Driving Forces of the Global Economy, Proceedings of the 2016 International Conference on Leadership, Innovation and Entrepreneurship, Dubai, UAE, 20-22 April 2016; Benlamri, R., Sparer, M., Eds.; Springer: Cham, Switzerland, 2017. [CrossRef]

Publisher's Note: MDPI stays neutral with regard to jurisdictional claims in published maps and institutional affiliations.

(C) 2020 by the authors. Licensee MDPI, Basel, Switzerland. This article is an open access article distributed under the terms and conditions of the Creative Commons Attribution (CC BY) license (http://creativecommons.org/licenses/by/4.0/). 